\title{
La Fortune. Thèmes, représentations, discours, études rassemblées par Yasmina Foehr-Janssens et Emmanuelle Métry
}

\section{G. Matteo Roccati}

\section{(2) OpenEdition}

Journals

Édition électronique

URL : https://journals.openedition.org/studifrancesi/38841

DOI : 10.4000/studifrancesi.38841

ISSN : 2421-5856

Éditeur

Rosenberg \& Sellier

Édition imprimée

Date de publication : 1 décembre 2004

Pagination : 329

ISSN : 0039-2944

\section{Référence électronique}

G. Matteo Roccati, « La Fortune. Thèmes, représentations, discours, études rassemblées par Yasmina Foehr-Janssens et Emmanuelle Métry », Studi Francesi [En ligne], 143 (XLVIII | II) | 2004, mis en ligne le 30 novembre 2015, consulté le 19 mai 2021. URL : http://journals.openedition.org/studifrancesi/ 38841 ; DOI : https://doi.org/10.4000/studifrancesi.38841

Ce document a été généré automatiquement le 19 mai 2021.

\section{cc) (†) $\odot$}

Studi Francesi è distribuita con Licenza Creative Commons Attribuzione - Non commerciale - Non opere derivate 4.0 Internazionale. 
La Fortune. Thèmes, représentations, discours, études rassemblées par Yasmina Foehr-Janssens et Emmanuelle Métry

G. Matteo Roccati 


\section{RÉFÉRENCE}

La Fortune. Thèmes, représentations, discours, études rassemblées par YASMINA FOEHR-

JANSSENS et EMMANUelLE MÉTRY, Genève, Droz («Recherches et rencontres. Publications de la Faculté des Lettres de l'Université de Genève», 19), 2003, pp. 224.

1 L'introduction (pp. 7-11) explique l'approche interdisciplinaire qui a présidé à la constitution du volume. Presque toutes les contributions concernent les mondes latin et médiéval: Nicole HECQUET-NOTI, «Fortuna» dans le monde latin: chance ou hasard? (pp. 13-29); Enrico NORELLI, Les avatars de Fortune dans les Actes apocryphes des Apôtres: Une comparaison avec les «Métamorphoses» d'Apulée (pp. 31-58); Emmanuelle MÉTRY, «Fortuna» et «Philosophia»: une alliance inattendue. Quelques remarques sur le rôle de la Fortune dans la «Consolation de Philosophie» de Boèce (pp. 59-70); André-Louis REY, «Tychè» et «Pronoia»: notes sur l'emploi de Fortune et Providence dans l'historiographie byzantine ancienne (pp. 71-92); Jean-Yves tiLliEtTE, Eclipse de la Fortune dans le haut moyen âge? (pp. 93-104); Jean WIRTH, L'iconographie médiévale de la roue de Fortune (pp. 105-127); Yasmina FOEHR-JANSSENS, La maison de Fortune dans l'«Anticlaudianus» d'Alain de Lille (pp. 129-144); Christopher LUCKEN, Les Muses de Fortune. Boèce, le «Roman de la Rose» et Charles d'Orléans (pp. 145-175); Jean-Claude MUEHLETHALER, Quand Fortune, ce sont les hommes. Aspects de la démythification de la déesse, d'Adam de la Halle à Alain Chartier (pp. 177-206); Jean LECOINTE, Figures de la Fortune et théorie du récit à la Renaissance (pp. 207-216). Le volume comporte également un index nominum et un index des manuscrits. 